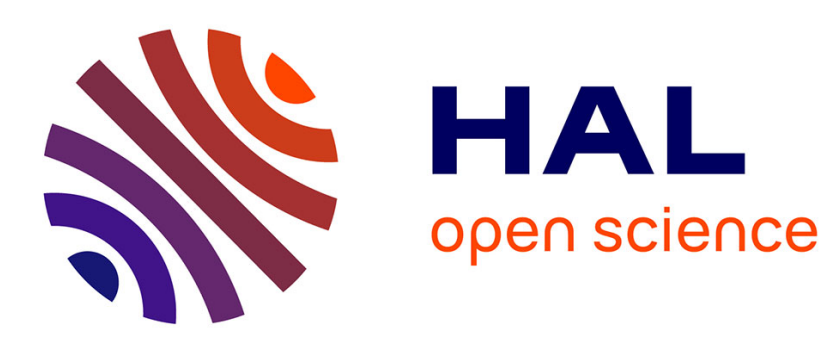

\title{
Fourier-transform infrared spectroscopy of ethyl lactate decomposition and thin film coating in a filamentary and a glow dielectric barrier discharge
}

\author{
Natalia G Milaniak, Gaétan Laroche, Françoise F. Massines
}

\section{- To cite this version:}

Natalia G Milaniak, Gaétan Laroche, Françoise F. Massines. Fourier-transform infrared spectroscopy of ethyl lactate decomposition and thin film coating in a filamentary and a glow dielectric barrier discharge. Plasma Processes and Polymers, 2021, 18 (7), pp.2000248. 10.1002/ppap.202000248. hal-03413261

\author{
HAL Id: hal-03413261 \\ https://hal.science/hal-03413261
}

Submitted on 3 Nov 2021

HAL is a multi-disciplinary open access archive for the deposit and dissemination of scientific research documents, whether they are published or not. The documents may come from teaching and research institutions in France or abroad, or from public or private research centers.
L'archive ouverte pluridisciplinaire HAL, est destinée au dépôt et à la diffusion de documents scientifiques de niveau recherche, publiés ou non, émanant des établissements d'enseignement et de recherche français ou étrangers, des laboratoires publics ou privés. 


\section{Fourier-transform infrared spectroscopy of ethyl}

\section{lactate decomposition and thin film coating in a}

\section{filamentary and a glow dielectric barrier}

\section{discharge}

Natalia Milaniak, Gaétan Laroche*, Françoise Massines*

N. Milaniak, Dr F. Massines

CNRS PROMES, Laboratoire PROcèdes Matériaux et Energie Solaire,

UPR 8521, Tecnosud, 66100 Perpignan, France

Email : Francoise.Massines@univ-perp.fr

N. Milaniak, Prof. G. Laroche

Laboratoire d'Ingénierie de Surface, Centre de Recherche sur les Matériaux Avances,

Département de génie des mines, de la métallurgie et des matériaux, Université Laval, 1045, Avenue de la Médicine, Québec G1V 0A6, Québec, Canada

Centre de recherche du CHU de Québec, Hôpital St François d'Assise, 10, Rue de

L’Espinay, Québec G1L 3L5, Québec, Canada 
Email: Gaetan.Laroche@gmn.ulaval.ca

KEYWORDS: FTIR, plasma, dielectric barrier discharge, thin film, FSK, biomaterials, chemical composition, in-situ spectroscopy

\section{ABSTRACT}

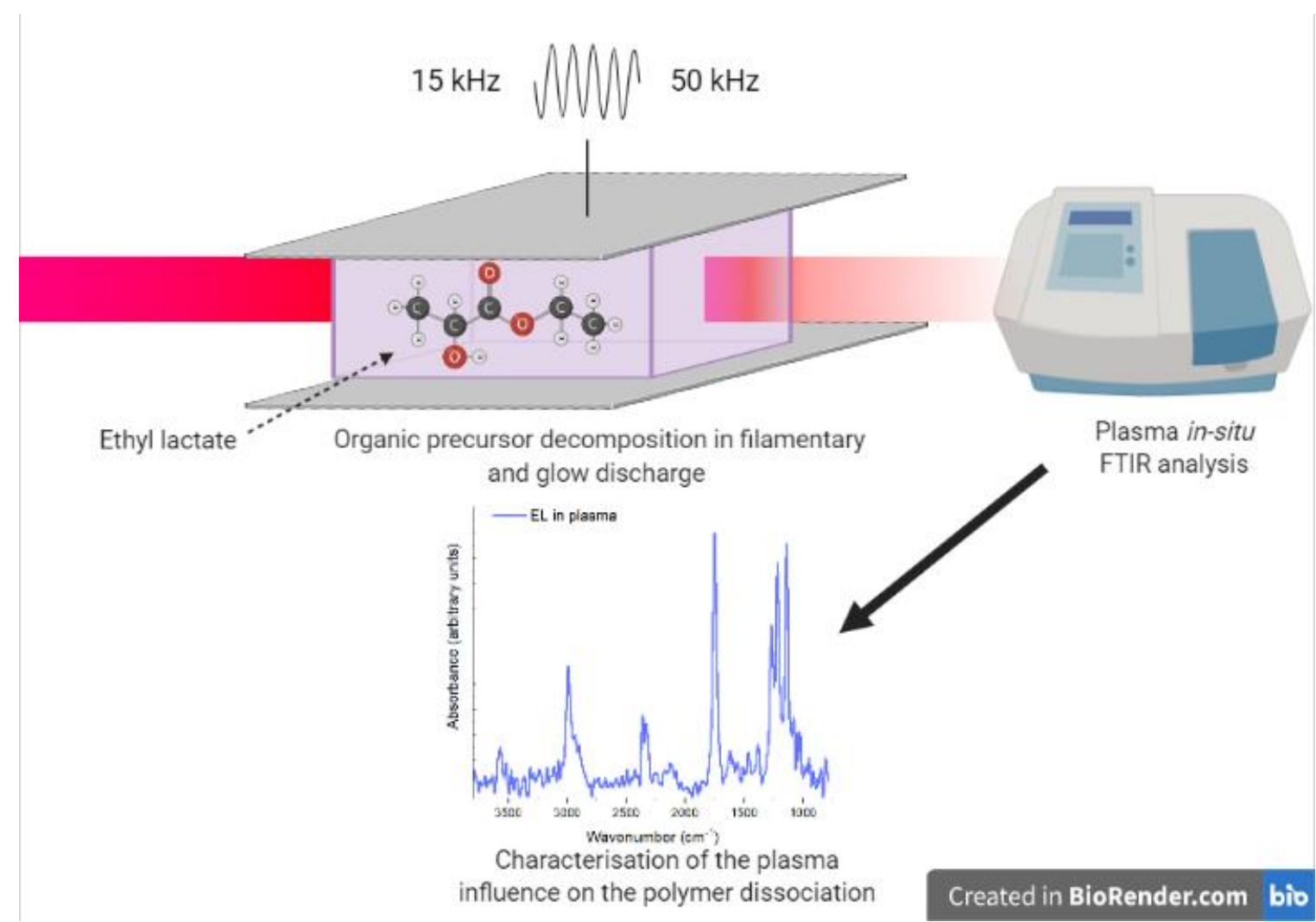

Glow and filamentary regimes of Atmospheric Pressure Plasma Enhanced Chemical

Vapor Deposition (AP-PECVD) in a planar Dielectric Barrier Discharge (DBD) configuration were compared for thin film deposition from ethyl lactate (EL) as a 
precursor. Space-resolved Fourier Transform Infrared Spectroscopy (FTIR) was used to study both the EL decomposition in the plasma phase and the composition of the thin film. EL chemical bonds concentration along the gas flow decreases progressively in the GDBD while it drastically oscillates in the FDBD, with values higher than that of the initial mixture. EL decomposition route depends on the discharge regime as the decrease of the concentration of the different investigated bonds are not the same for an identical amount of energy provided to the EL molecules. $\mathrm{CO}_{2}$ is systematically formed in the plasma reaching a maximum concentration of $25 \mathrm{ppm}$ in the FDBD and $40 \mathrm{ppm}$ in the GDBD mode. 


\section{Introduction}

Thin film deposition by Plasma Enhanced Chemical Vapor Deposition (PECVD) on silicon wafers has first been investigated in the 60s. Later, the PECVD technology was extended to atmospheric plasma (AP PECVD) $)^{1-6}$. The main advantage of atmospheric pressure plasma is the ability to lower the costs for treating materials by avoiding pumping systems and enabling large surface treatments by a continuous process. Thanks to its simple scalability from small laboratory reactors to large industrial installations and the homogeneity of deposited layer, $\mathrm{DBD}^{7-9}$ is a good candidate for making a polymer thin film ${ }^{10-13}$. For this reason, non-equilibrium atmospheric pressure plasma in a Dielectric Barrier Discharge (DBD) configuration is an interesting option for treatment and coating of surfaces.

As reported by Massines et al. ${ }^{14}$, five different discharge regimes are possible while working with dielectric barrier discharges at atmospheric pressure. These regimes are filamentary DBD (FDBD), glow like DBD (GLDBD), glow DBD (GDBD), Townsend DBD (TDBD) and radiofrequency DBD. This work will focus on two of them, selected for their differences in electron energy levels and electron density. On one hand, FDBD is characterized by a multitude of microdischarges with a high electron density $\left(10^{13}\right.$ to $10^{14}$ $\mathrm{cm}^{-3}$ ) for very short duration (100ns). On the other hand, GDBD is characterized by a homogenous discharge with a lower electron density $\left(10^{10}\right.$ to $\left.10^{11} \mathrm{~cm}^{-3}\right)$ but a longer duration $(\mu \mathrm{s})^{14}$. Previous works have shown that in identical atmospheres, FDBD and GDBD could lead to different surface treatments. ${ }^{15,16}$ Accordingly, the aim of this work is 
to better understand the differences of the chemistry occurring in the two aforementioned DBD modes. These two discharge regimes are easily obtained in $\mathrm{Ar}-\mathrm{NH}_{3}$ Penning gas mixture. GDBD is observed for higher frequencies. The higher repetition rate maintained a higher energy in the gas gap and induces a higher power ${ }^{14}$.

Ethyl lactate (EL) was chosen as vaporized liquid precursor. This choice was motivated by two reasons. First, EL displays a wide variety of chemical bonds with various dissociation energies. These different bonds are easily detected by infrared absorption spectroscopy, allowing an in-situ observation of the molecule transformation. Second, the plasma polymerization process of EL is likely to produce a "polylactic acid like" polymer. Polylactic acid presents a great interest related to its biodegradability by water or microorganism ${ }^{17,18}$ and its non-toxicity. It could be used for controlled drug release for biomedical application ${ }^{19-21}$. For this reason, scientists started to pay close attention to the synthesis of "polylactic acid like" films through plasma-based technologies. Ethyl lactate (EL) plasma polymer (EL PP) ${ }^{13,22,23}$ was shown to be biodegradable ${ }^{24}$, therefore paving the way for its use as a drug delivery system.

The decomposition scheme of ethyl lactate has been studied using several characterization techniques among which mass spectrometry ${ }^{12,25}$, x-ray photoelectron spectroscopy ${ }^{10}$, and electrical characterizations ${ }^{6}$. In this work, Fourier Transform Infrared (FTIR) absorption spectroscopy was used. This method is convenient to characterize both the plasma and the thin film. Space resolved measurements were used to analyze the decomposition of EL in the plasma and the thin film composition as a function of the gas residence time in the 
plasma $^{26}$. On one hand, the decomposition kinetics of EL in both FDBD and GDBD plasma regimes was ascertained through in-situ FTIR measurements. On the other hand, the thin film composition was also characterized by FTIR along its whole length and correlated with the EL decomposition scheme along the plasma.

\section{Materials and methods}

\subsection{Materials}

The reactor chamber was filled with nitrogen (Alphagaz 1, 99.999\% purity) to avoid arcs formation around the electrodes. Then the vaporized liquid precursor was injected between the electrodes, together with the carrier gases. The organic precursor chosen for the study was (-)-Ethyl L-lactate $\mathrm{C}_{5} \mathrm{H}_{10} \mathrm{O}_{3}$ (manufactured by Sigma-Aldrich, USA) with confirmed purity at $97.5 \%$. The carrier gas was argon (Alphagaz 1, 99.999\% purity) as the main gas and $\mathrm{NH}_{3}$ (Alphagaz 1, 99.999\% purity) for ensuring discharge stability. The reactor chamber was filled with nitrogen (Alphagaz 1, 99.999\% purity) for ensuring discharge stability.

\subsection{Methods}

\subsubsection{Plasma reactor}

The plasma reactor is a plane-to-plane Dielectric Barrier Discharge (DBD) already described elsewhere ${ }^{27}$. Briefly, it was composed of two electrodes $(2 \mathrm{~cm} \times 5 \mathrm{~cm})$, one is connected to a high voltage (HV) and the other is connected to the ground. The electrodes were metallized on the rear face of the alumina plates of $69 \mathrm{~mm}$ x $69 \mathrm{~mm}$ and of $1 \mathrm{~mm}$ in thickness. Two transformers (Boige et Vignal) are used for these experiments. The first 
one is operated at a frequency range from 1 to $10 \mathrm{kHz}$ whereas the second one enables working between $50 \mathrm{kHz}$ to $100 \mathrm{kHz}$. Both transformers made it possible to work at amplified voltages (Crest CC4000 audio amplifier) ranging between 1 and $15 \mathrm{kV}$ with waveforms selected using an Agilent 33210 waveform generator. The gap between the alumina plates was kept at $2 \mathrm{~mm}$. EL PP was deposited on top of a $275 \mu \mathrm{m}$ thick round silicon wafer of $5.08 \mathrm{~cm}$ in diameter. The deposition area was the same than that of the electrodes, that was $2 \times 5 \mathrm{~cm}^{2}$. The characteristics of the two DBDs of this work are given in Table 1.

Table 1. Characteristics of the chosen DBD regimes ${ }^{14}$.

\begin{tabular}{|c|c|c|}
\hline Property/Type of DBD & $\begin{array}{c}\text { Filamentary } \\
\text { FDBD }\end{array}$ & $\begin{array}{l}\text { Glow } \\
\text { GDBD }\end{array}$ \\
\hline Frequency & $15 \mathrm{kHz}$ & $50 \mathrm{kHz}$ \\
\hline Voltage $[k \mathrm{~V}]$ & 3 & 1.3 \\
\hline Average power $[\mathrm{W}]$ & 1 & 4 \\
\hline Average power density $\left[\mathrm{W} / \mathrm{cm}^{2}\right]$ & 0.1 & 0.4 \\
\hline Homogeneity of the discharge & No & Yes \\
\hline Maximum electron density $\left[1 / \mathrm{cm}^{3}\right]$ & $10^{13}-10^{14}$ & $10^{10}$ \\
\hline
\end{tabular}

The plasma reactor was pumped down to $2.2 \times 10^{-2}$ Torr, and then filled with nitrogen (to reach a pressure of 760 Torr. Initial filling with nitrogen minimizes arc formation around the electrodes, as nitrogen has 10 times higher breakdown voltage than argon, which has been chosen as the carrier gas due to its lower breakdown voltage, lower cost compared to 
helium, and its inability to incorporate itself within the molecular structure of the plasma polymer, as shown by Laurent et al. ${ }^{22}$

An aerosol made of $1.1 \mathrm{slm}$ of argon + ethyl lactate by the means of an atomizer (TSI atomizer model 3076 creating droplets in the size range between 0.3 and $3 \mu \mathrm{m}$ ) was diluted in 1.9 slm of argon $+133 \mathrm{ppm}$ of $\mathrm{NH}_{3}$, making a total flow of $\mathrm{Ar}$ of 3 slm containing 350 ppm of EL and $133 \mathrm{ppm}$ of $\mathrm{NH}_{3}$. This gas mixture was injected in the reactor through a 0.1 $\mathrm{x} 4 \mathrm{~cm}^{2}$ slit located $4 \mathrm{~cm}$ away from the DBD. Two zinc selenide (ZnSe) IR transparent windows $\left(2 \times 2 \times 70 \mathrm{~mm}^{3}\right)$ were placed parallel to the gas stream in order to maintain the laminar flow by avoiding any gas flow perturbations. The gas injection was perpendicular to the long axis $(5 \mathrm{~cm})$ of the electrode and the spectral acquisition was performed every 2 $\mathrm{mm}$ along the $2 \mathrm{~cm}$-wide plasma. Therefore, the position of the measurement along the plasma can be correlated to the residence time and the mean energy sensed by the species ${ }^{28 \text {, }}$ 29. The voltage amplitude for each regime was chosen to ensure a stable discharge and reproducibility of the results. The power being the integral of the product of the measured voltage and current over a cycle divided by the cycle duration, it is the result of the chosen plasma parameters.

\subsection{In flight precursor FTIR}

The FTIR setup used to record in-flight and in-situ spectra of the precursor, in both gaseous and plasma phases, is described elsewhere. ${ }^{26}$ The spectrometer was an Agilent Cary 670 equipped with a $\mathrm{KBr}$ beam splitter and a narrowband MCT-A detector. The spectra were recorded between 4000 and $400 \mathrm{~cm}^{-1}$ by co-adding 256 scans at a resolution 
of $4 \mathrm{~cm}^{-1}$. The absorption length across the plasma was $10 \mathrm{~cm}$, corresponding to a backand-forth passage along the long axis of the electrodes.

The background spectrum was recorded in pure argon without plasma while the plasma spectra were recorded 5 minutes after injecting ethyl lactate at a concentration of 350 ppm in argon in the plasma reactor. This was done to ensure constant and reproducible amount of EL in the gas between the electrodes at the time of lighting up the discharge. The infrared beam path located outside the reactor was always purged with dry $\mathrm{CO}_{2}$-free air. The plasma reactor was systematically pumped down between each experiment. Of note, $\mathrm{CO}_{2}$ absorption was never observed without plasma. After each measurement with EL, the plasma region was flushed with pure argon. Another spectrum was recorded in these conditions and subtracted from that of the EL plasma. This enabled to eliminate the spectral contribution of adsorbed ethyl lactate on the ZnSe windows.

The resulting spectra were then smoothed using Origin FFT filter with 5 points to improve the accuracy of the measured peak absorbances. Five analysis positions were considered for both plasma and thin film analysis at $0 \pm 1,5 \pm 1,10 \pm 1,15 \pm 1,19 \pm 1 \mathrm{~mm}$ along the $2 \mathrm{~cm}$ wide plasma, the corresponding mean residence time of the gases in the plasma are $1.2 \pm 1.2,6.0 \pm 1.2,12.0 \pm 1.2,18 \pm 1.2$ and $24 \pm 1.2 \mathrm{~ms}$ respectively. Calibration curves were built to follow the concentration of each of the EL chemical bonds by measuring their infrared absorbance while injecting EL between the electrodes at concentrations ranging 0 to $700 \mathrm{ppm}$ without igniting the plasma. The quantification limits, defined as being ten times the standard deviation of noise fluctuation ${ }^{30}$, are reported in Table $2 . \mathrm{CO}_{2}$ being a decomposition product of ethyl lactate ${ }^{11}$, it was calibrated by measuring the integrated 
absorbance of the $2340-2360 \mathrm{~cm}^{-1}$ feature of infrared spectra recorded with known amounts concentration of $\mathrm{CO}_{2}$ introduced in the plasma chamber.

\subsection{Thin film FTIR}

A Nicolet 6700 (THERMO Scientific) FTIR spectrometer purged with $\mathrm{CO}_{2}$-free dry air was used to analyze the thin films. The thin film transmission spectra were the results of the co-addition of 64 scans at a resolution of $4 \mathrm{~cm}^{-1}$. The spectrum of a clean silicon wafer was first recorded and subtracted from the spectrum of the plasma polymerized EL on silicon. Measurements were made with a $2 \mathrm{~mm}$ spatial resolution along the direction of the gas flow (i.e. $2 \mathrm{~cm}$ ), enabling to compare spectra recorded at the corresponding positions in the plasma and on the thin film.

\section{Results and discussion}

The interest of ethyl lactate for this study came from its efficient absorption in infrared useful for its characterization by FTIR, its biocompatibility and non-toxicity. It also has well defined and distinctive energies for dissociating a given bond within the molecule Figure 1, which also makes it an interesting candidate to determine the plasma chemical reactivity. 


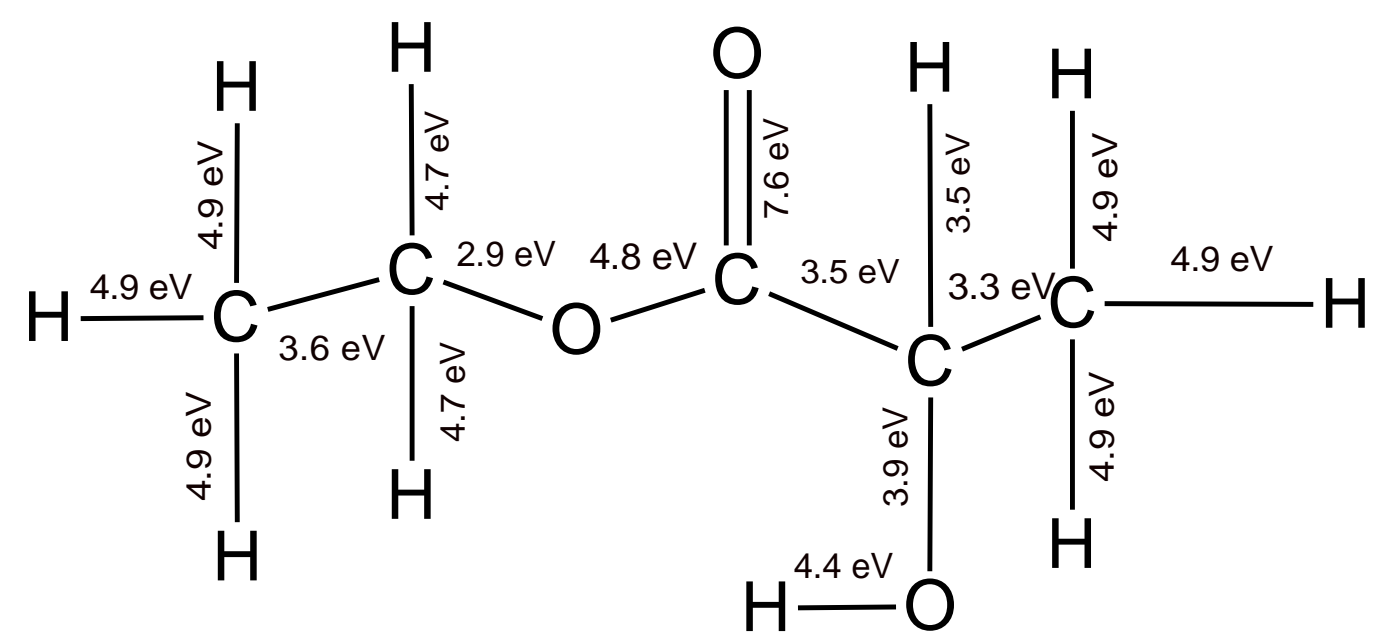

Figure 1. Structure of EL with energies needed to dissociate its chemical bonds ${ }^{31}$.

\subsection{FTIR spectra}




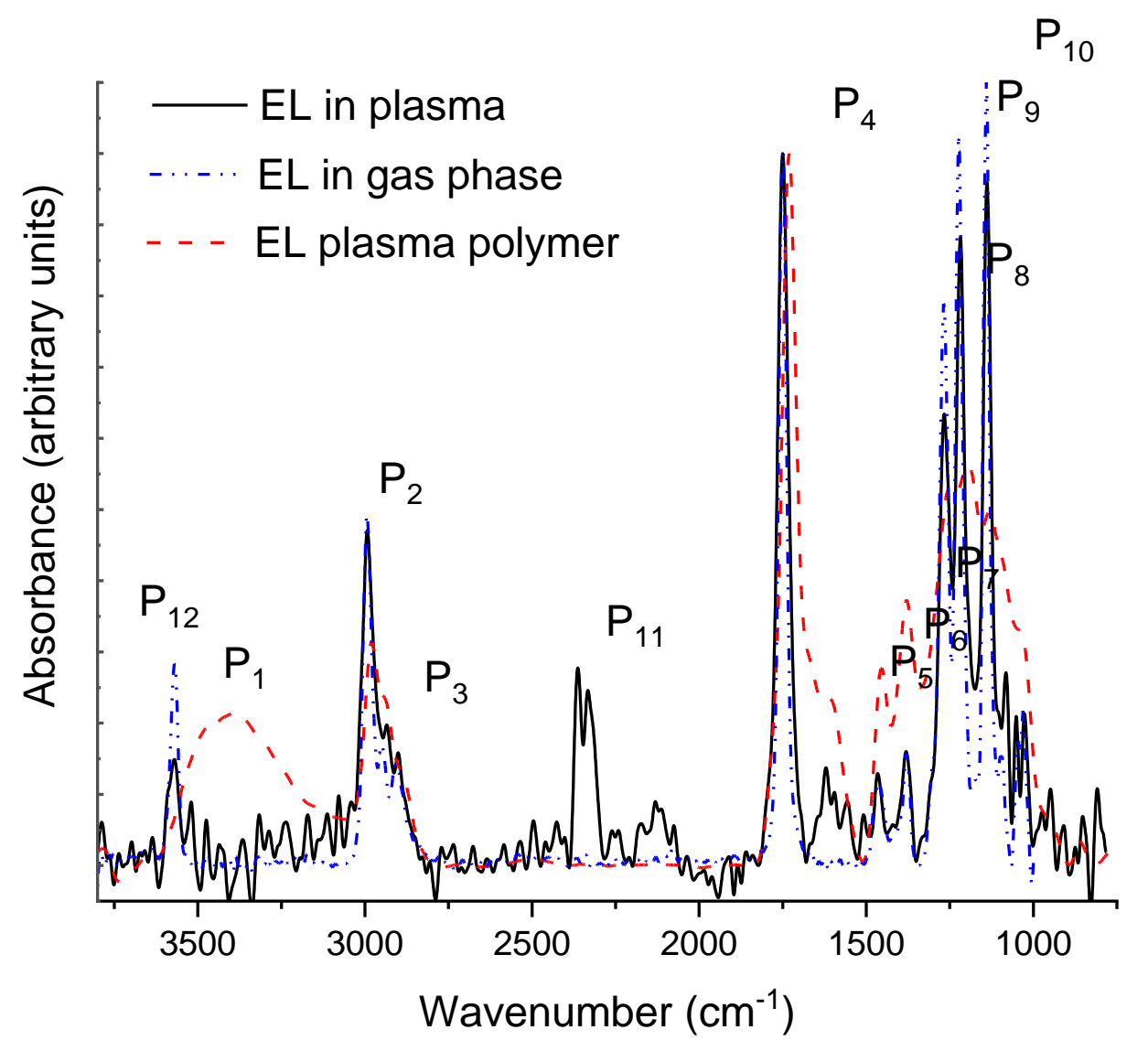

Figure 2. Typical normalized FTIR spectra of ethyl lactate in the gas with (solid black line) and without (blue dash-dotted line) plasma, and of the "polylactic acid like" polymer thin film (red dashed line) state.

Figure 2 presents normalized spectra (to the peak at $1750 \mathrm{~cm}^{-1}$ ) of EL in-gas phase with and without plasma and of the "polylactic acid like" polymer coating. All three spectra show the usual IR absorption of EL, as listed in Table 2. However, differences are observed. The peaks in EL in the gas phase are easily distinguishable, compared to the 
solid phase, where overlapping between absorption bands can be observed. This is due to the lesser number of interactions between molecules in the gas phase as compared to the thin film. In addition, the plasma spectrum shows significantly higher noise-to-signal ratio compared to the gas phase without plasma, due to the electromagnetic noise. The first striking observation is the almost complete disappearance of the $\mathrm{OH}$ stretching mode feature $\left(\mathrm{P}_{1}\right)$ in both the gas and plasma made with EL due to the absence of intramolecular interactions in these phases. In addition, the absorbance of $\mathrm{P}_{12}$ (free $\mathrm{OH}$ stretching) decreases from the gas phase to the plasma, with a concomitant appearance of $\mathrm{P}_{1}$ in the deposited thin film spectrum. Another observation that is worth mentioning is the creation of $\mathrm{CO}_{2}$, manifested through the feature at $2340-2360 \mathrm{~cm}^{-1}\left(\mathrm{P}_{11}\right)$, without any gaseous $\mathrm{H}_{2} \mathrm{O}$ production, only observed in the plasma.

Table 2. Infrared assignments of the observed absorptions: ethyl lactate and carbon dioxide $^{11,32-34}$ and their quantification limits in the experimental conditions of this work.

\begin{tabular}{|c|c|c|c|}
\hline & Wavenumber $\left(\mathrm{cm}^{-1}\right)$ & Vibrational mode & Quantification limit (ppm) \\
\hline $\mathbf{P}_{1}$ & $3570-3200$ (broad) & OH stretching (intermolecular) & 150 \\
\hline $\mathbf{P}_{2}$ & 2990 & $\mathrm{CH}_{3}$ asymmetric stretching & 90 \\
\hline $\mathbf{P}_{3}$ & 2940 & $\mathrm{CH}_{2}$ asymmetric stretching & 186 \\
\hline $\mathbf{P}_{4}$ & 1750 & $\begin{array}{l}\text { Ester group, } \mathrm{C}-(\mathrm{C}=\mathrm{O})-\mathrm{R} \\
\text { Ketone, } \mathrm{R}_{1}-(\mathrm{C}=\mathrm{O})-\mathrm{R}_{2} \\
\text { asymmetric stretching }\end{array}$ & 38 \\
\hline $\mathbf{P}_{5}$ & 1620 & $\begin{array}{l}\text { Carboxylate group, } \\
\mathrm{R}-(\mathrm{C}=\mathrm{O})-\mathrm{O}\end{array}$ & \\
\hline $\mathbf{P}_{6}$ & 1455 & $\mathrm{CH}_{\mathrm{x}}$ bending & \\
\hline $\mathbf{P}_{7}$ & 1380 & $\begin{array}{l}\text { Primary or secondary, OCO-H } \\
\text { (intramolecular) in-plane } \mathrm{OH} \\
\text { bend }\end{array}$ & 158 \\
\hline $\mathbf{P}_{8}$ & 1266 & $\mathrm{CH}(\mathrm{OH}) \mathrm{CH}_{3}$ bending & 158 \\
\hline $\mathbf{P}_{9}$ & 1222 & $\mathrm{C}-\mathrm{OC}(=\mathrm{O})$ stretch & \\
\hline
\end{tabular}




\begin{tabular}{|c|c|c|c|}
\hline $\mathbf{P}_{10}$ & 1140 & $\mathrm{C}-\mathrm{OH}$ asymmetric stretching & 44 \\
\hline $\mathbf{P}_{11}$ & $2360-2340$ & $\mathrm{C}=\mathrm{O}$ in $\mathrm{CO}_{2}$ & 5 \\
\hline $\mathbf{P}_{12}$ & 3575 & Free $\mathrm{OH}$ & \\
\hline
\end{tabular}

\subsection{In-situ plasma FTIR analysis}

\subsubsection{Glow $D B D$}

Figure 3 presents the plasma IR absorptions at 5 different positions in a GDBD along the gas flow e.g. for 5 different gas residence times in the plasma. Peak identification reported in the graphs corresponds to those of Table 2. The overall tendency is that the EL absorption bands decrease when this precursor residence time in the gas increases, showing a continuous fragmentation of the molecule along the plasma. At the same time, the concentration of $\mathrm{CO}_{2}\left(\mathrm{P}_{11}\right)$ increases along the plasma. As no $\mathrm{H}_{2} \mathrm{O}$ absorption is observed, the $\mathrm{CO}_{2}$ formation cannot be explained by combustion reactions, meaning that the discharge does not entirely decompose the molecule (as in combustion process for instance) but mostly fragments EL. 


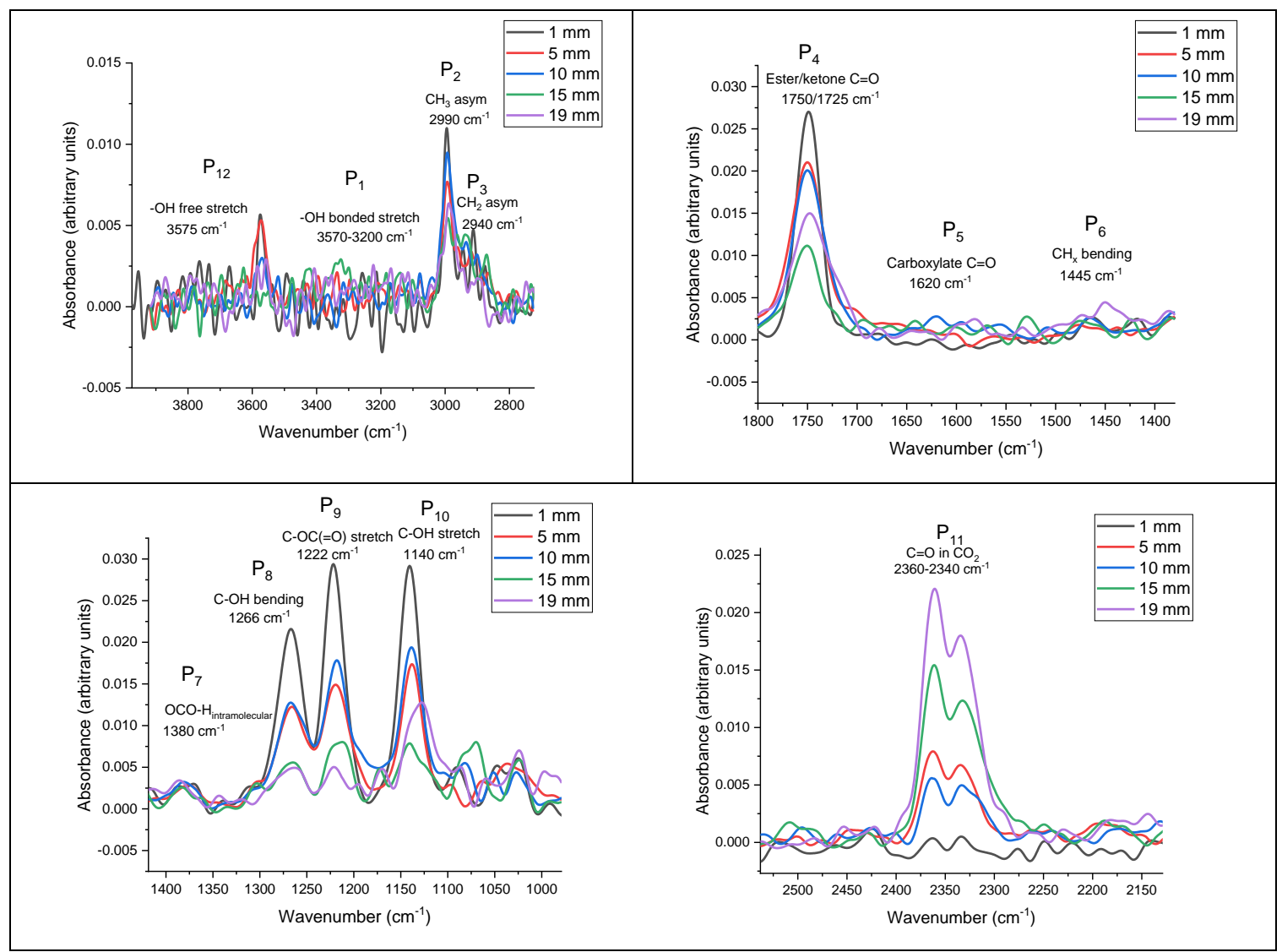

Figure 3. EL bands by position in GDBD regime from the plasma phase spectra. Higher is the position, the longer is the EL residence time in the plasma.

From Figure 3, it can be seen that the so-called decrease of the $\mathrm{P}_{12}$ absorbance begins between positions 5 and $10 \mathrm{~mm}$ in the plasma, therefore showing that dissociation of this chemical group from the overall EL molecule starts somewhere from these positions.

It is also interesting to observe the behavior of the $\mathrm{CH}_{2}$ and $\mathrm{CH}_{3}$ groups of the EL molecule in the plasma, which can be followed through either their stretching $\left(\mathrm{P}_{2}\right.$ and $\left.\mathrm{P}_{3}\right)$ or bending $\left(\mathrm{P}_{6}\right)$ modes. As may be seen in Figure 3, $\mathrm{CH}_{\mathrm{x}}$ stretching mode features $\left(\mathrm{P}_{2}\right.$ and $\left.\mathrm{P}_{3}\right)$ remain present for all plasma positions, whereas $\mathrm{CH}_{2}$ and $\mathrm{CH}_{3}$ bending $\left(\mathrm{P}_{6}\right)$ is much less intense. This is a clear indication that some of the $\mathrm{CH}_{2}$ and $\mathrm{CH}_{3}$ groups of EL lose some of their 
hydrogen atoms to form $\mathrm{CH}$ containing moieties, which still can give rise to $\mathrm{C}-\mathrm{H}$ stretching mode spectral contributions but, of course, cannot provide bending vibrations, as at least two hydrogen atoms need to be bound to a single carbon for such as spectral contributions to be observed. Finally, the absorbance of the $\mathrm{C}=\mathrm{O}\left(\mathrm{P}_{4}\right), \mathrm{C}-\mathrm{OC}\left(\mathrm{P}_{9}\right)$, and $\mathrm{C}-\mathrm{OH}\left(\mathrm{P}_{10}\right)$ stretching mode features also tends to decrease along the plasma, while their wavenumbers remain in the range typical of esters $\left(\mathrm{P}_{9}\right)$ and/or aldehyde $\left(\mathrm{P}_{10}\right)$ showing that these bonds are still present in the plasma phase.

\subsubsection{Comparison of glow and filamentary $\mathrm{DBD}$}

Figure 4 shows the comparison of the concentration evolution with the energy provided per EL molecule injected in the plasma of some selected chemical groups for both GDBD and FDBD as a function of the energy provided per EL molecule injected in the plasma. Energy is the product of the gas residence time and the DBD power. This energy could potentially be transferred to the EL molecule and to the plasma-dissociated EL molecule fragments. As the GDBD power is four time larger than that of the FDBD (Table 1) with identical EL concentration, the energy per EL molecule is also four times larger in the GDBD. The conversion from absorbance to concentration was made based on the aforementioned calibration curves (see Materials and Methods). The selected chemical groups are related to $\mathrm{C}-\mathrm{O}, \mathrm{C}-\mathrm{H}$, and $\mathrm{O}-\mathrm{H}$ bonds of $\mathrm{EL}$ and $\mathrm{CO}_{2}$ molecules. The error bars are obtained by calculating the error propagation from intensity to concentration, from the standard deviation of the intensity measurements and the uncertainty of the calibration curves. 
Generally speaking, the various chemical species concentration evolution with the energy provided per EL molecule follows a similar trend for both GDBD and FDBD. However, GDBD leads to a more gradual decomposition of EL whereas FDBD shows rather large oscillations. These concentration oscillations in FDBD are likely due to variation in the plasma homogeneity. Indeed, FTIR measurements last about a minute while the repetition rate of the FDBD is $15 \mathrm{kHz}(0.067 \mathrm{~ms})$. Accordingly, FTIR measurements should lead to concentration values that would be averaged in time. In addition, the IR absorption path length is much longer $(10 \mathrm{~cm})$ than the microdischarge radius (typically $200 \mu \mathrm{m})^{14}$ with a mean distance between two microdischarges in the range of $\mathrm{mm}$. These two observations point toward the fact that the various chemical group observed concentration oscillations are real. Interestingly, the $\mathrm{CH}_{3}$ and $\mathrm{CH}_{2}\left(\mathrm{P}_{2}\right.$ and $\left.\mathrm{P}_{3}\right)$ concentrations sometimes reach higher values than what would have been expected from the single injection of EL, indicating that another source is responsible for these moieties production. Because a very high concentration of energetic species is reached locally and for a short time in a FDBD as compared to GDBD, in which energetic species concentrations are lower and more uniformly distributed, it is theorized that surface etching occurs in FDBD, therefore leading to this increase of hydrocarbon moieties in the plasma discharge. 


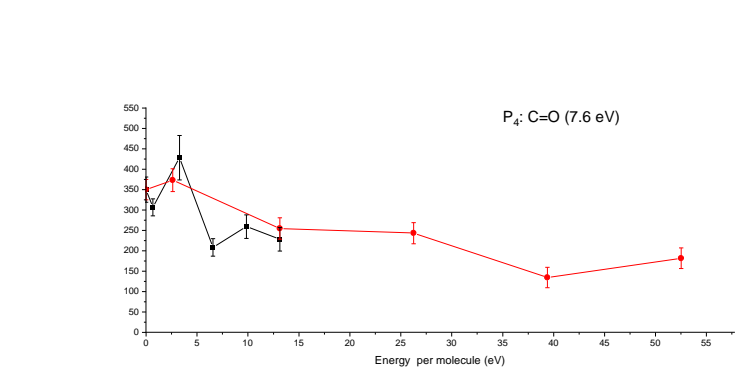

\section{- FDBD}

- GDBD

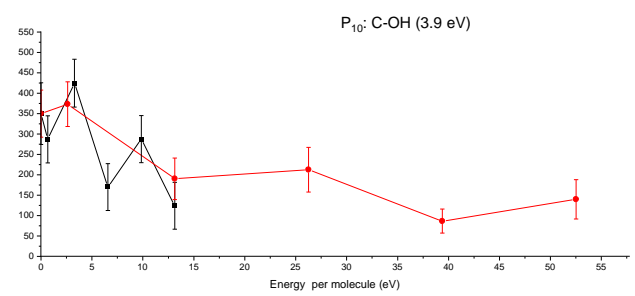

$\mathrm{P}_{9}: \mathrm{C}-\mathrm{OC}(=\mathrm{O})(2.9 \mathrm{eV})$
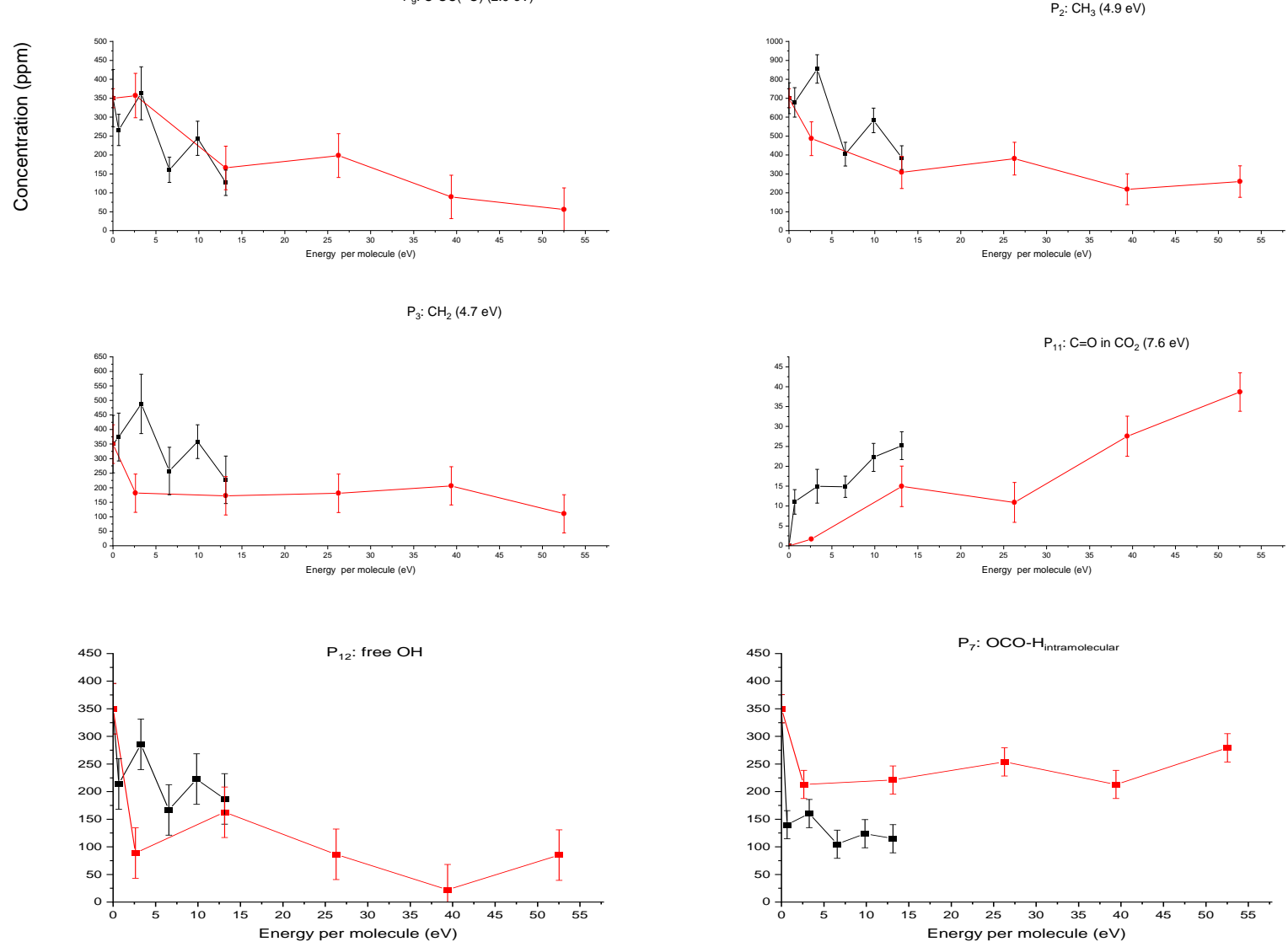
Figure 4. Evolution of concentration of different IR absorption bands in both GDBD (red) and FDBD (black) as a function of energy per EL molecule in the plasma phase. The values at $0 \mathrm{eV}$ were taken from vaporized EL without plasma.

For FDBD the $\mathrm{C}=\mathrm{O}\left(\mathrm{P}_{4}\right)$ chemical bond behavior shows that the concentration in the plasma oscillates in the first two positions and then stabilizes at around $225 \mathrm{ppm}$ at 10 $\mathrm{eV} /$ molecule and does not change significantly as more energy per molecule is provided. In this plasma regime, both $\mathrm{C}-\mathrm{OH}\left(\mathrm{P}_{10}\right)$ and $\mathrm{C}-\mathrm{OC}\left(\mathrm{P}_{9}\right)$ follow this similar oscillating trend between positions, but in general shows a decrease from the beginning to the end of the plasma zone and reaches a minimum of around $125 \mathrm{ppm}$. When $3 \mathrm{eV} /$ molecule are provided, both $\mathrm{CH}_{3}\left(\mathrm{P}_{2}\right)$ and $\mathrm{CH}_{2}\left(\mathrm{P}_{3}\right)$ show a greater concentration that due to the initially injected EL, probably due to the fact that the FDBD could induce etching of the surface and reintroduction of fragments into the plasma region. With the increasing of the energy provided to each EL molecule, the concentrations of these hydrocarbon moieties decrease to reach 450 and $250 \mathrm{ppm}$, respectively. On the other hand, the concentration of free $\mathrm{OH}$ $\left(\mathrm{P}_{12}\right)$ in the FDBD decreases by position to reach $200 \mathrm{ppm}$ for $15 \mathrm{eV} /$ molecule. Interestingly, the amount of OCO- $\mathrm{H}_{\text {intra }}\left(\mathrm{P}_{7}\right)$ decreases significantly as EL enters the plasma and then reaches a plateau of around $100 \mathrm{ppm}$ at $6 \mathrm{eV} /$ molecule which does not change with more energy being provided to each molecule.

As mentioned previously, the concentration changes in GDBD are distinctive of those in FDBD. 
In GDBD $\mathrm{C}=\mathrm{O}\left(\mathrm{P}_{4}\right), \mathrm{C}-\mathrm{OH}\left(\mathrm{P}_{10}\right)$ and $\mathrm{CH}_{3}\left(\mathrm{P}_{2}\right)$ show a similar behavior with the increasing energy, where a slight decrease is observed until $40 \mathrm{eV} / \mathrm{molecule}$ is reached and then plateaus at 200, 150 and 300 ppm, respectively. The concentration of C-OC $\left(\mathrm{P}_{9}\right)$ bonds decreases steadily with the increasing energy and reaches a concentration very close to 0 ppm, coherent with the fact that this is the bond with the lower dissociation energy in the EL molecule. A decrease is observed at $4 \mathrm{eV} /$ molecule for $\mathrm{CH}_{2}\left(\mathrm{P}_{3}\right)$ concentration, which plateaus at $175 \mathrm{ppm}$ between 2.5 and $40 \mathrm{eV} / \mathrm{molecule}$, and then decreases to $100 \mathrm{ppm}$ at 52 $\mathrm{eV} /$ molecule. The free $\mathrm{OH}$ group concentration $\left(\mathrm{P}_{12}\right)$ shows a rather continuous decrease up to $40 \mathrm{eV} / \mathrm{molecule}$ where it reaches a concentration close to $0 \mathrm{ppm}$. A slight increase is observed at the very exit of the plasma discharge area, suggesting creation of free $\mathrm{OH}$ likely due to the important fragmentation of the whole molecule at these energy levels. Similarly to what was observed with FDBD, the concentration of $\mathrm{OCO}-\mathrm{H}_{\text {intra }}\left(\mathrm{P}_{7}\right)$ in the GDBD decreases from 350 to $210 \mathrm{ppm}$ at $4 \mathrm{eV} /$ molecule, then plateaus up to $40 \mathrm{eV} /$ molecule to finally slightly increase to reach final concentration of $300 \mathrm{ppm}$.

\subsubsection{Carbon dioxide creation from ethyl lactate dissociation in the plasma phase}

One of the important byproducts of plasma dissociation of EL is $\mathrm{CO}_{2}$, which necessarily comes from the dissociation of either $\mathrm{CO}-\mathrm{C}, \mathrm{CO}-\mathrm{H}$ or $\mathrm{C}=\mathrm{O}$ moieties. Thus, the concentration of $\mathrm{CO}_{2}$ was plotted as a function of the consumption of these oxygencontaining functionalities. Among the plotted curves, only the consumption behaviors of $\mathrm{C}-\mathrm{OC}\left(\mathrm{P}_{9}\right)$ in GDBD regime and $\mathrm{C}=\mathrm{O}\left(\mathrm{P}_{4}\right)$ in FDBD discharges were shown to follow 
trends that could be reasonably defined by mathematical equations. The results are presented in Figure 5..

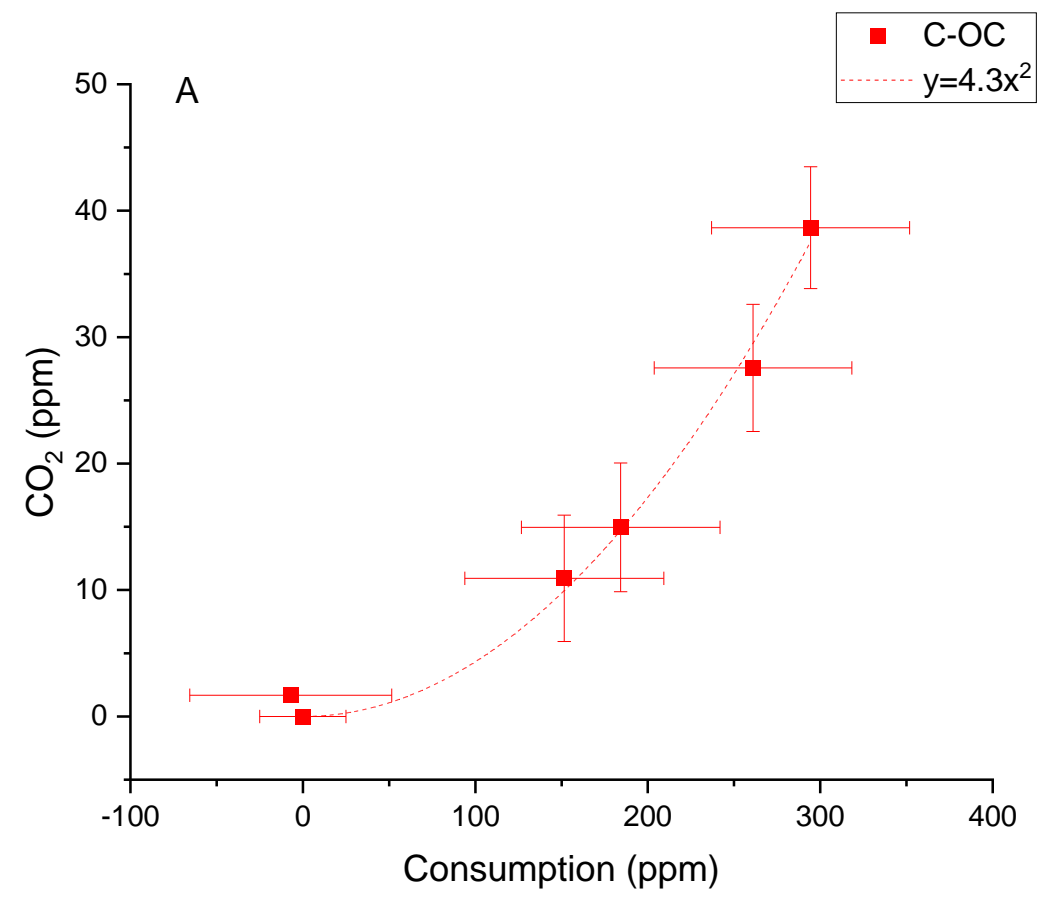




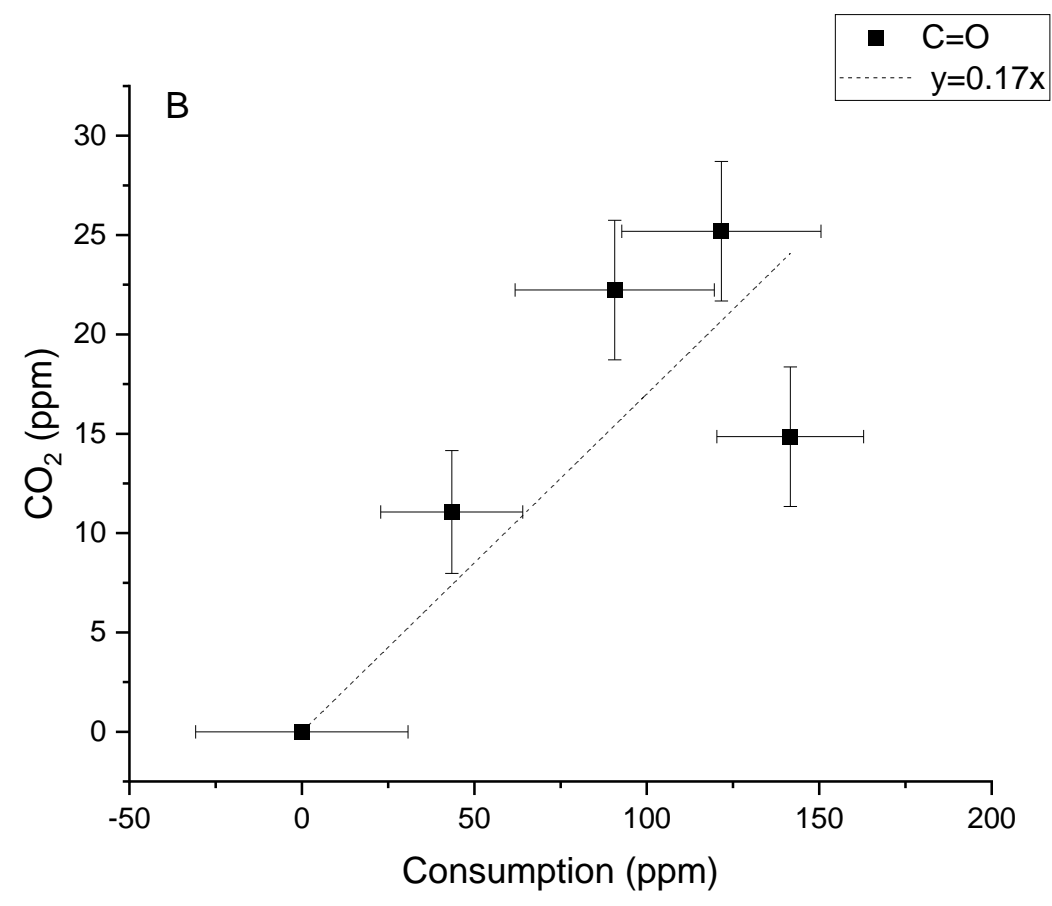

Figure 5. $\mathrm{CO}_{2}$ concentration as a function of the decomposition of A: $\mathrm{C}-\mathrm{OC}\left(\mathrm{P}_{9}\right)$ for GDBD and $\mathrm{B}$ : $\mathrm{C}=\mathrm{O}\left(\mathrm{P}_{4}\right)$ bands for FDBD.

As it is seen in Figure 5, the formation of $\mathrm{CO}_{2}$ as a function of the $\mathrm{C}=\mathrm{O}$ group decomposition in the filamentary discharge follows a simple linear regression, typical of a first order reaction and reaches a maximum of $25 \mathrm{ppm}$. This suggests a reaction $\mathrm{CO}+$ $1 / 2 \mathrm{O}_{2} \leftrightarrow \mathrm{CO}_{2}$. Conversely, the creation of $\mathrm{CO}_{2}$ in GDBD regime rather follows a quadratic relationship, characteristic of a second order reaction, and reaches a maximum of $40 \mathrm{ppm}$. The reaction that could be occurring in this case would be that of two CO-C fragments.

Interestingly, some data points show production of $\mathrm{CO}_{2}$ concomitant with the increase (seen as a "negative" consumption on the curve) of $\mathrm{C}-\mathrm{OC}$, which suggests that the $\mathrm{CO}_{2}$ 
may arise from the etching of the already deposited plasma coating. In FDBD, the $\mathrm{CO}_{2}$ concentration never exceeds $25 \mathrm{ppm}$. Even though the origin of these differences between GDBD and FDBD regimes has not been elucidated yet, it clearly highlights different EL decomposition kinetics and reaction efficiencies. In GDBD, the production of $\mathrm{CO}_{2}$ is clearly related to the consumption of $\mathrm{C}-\mathrm{OC}\left(\mathrm{P}_{9}\right)$ ) chemical bonds, whereas in FDBD a linear dependency between $\mathrm{C}=\mathrm{O}$ dissociation and $\mathrm{CO}_{2}$ creation was observed.

\subsection{Thin film spectra}

3.2.1. Comparison between plasma and solid phase spectra

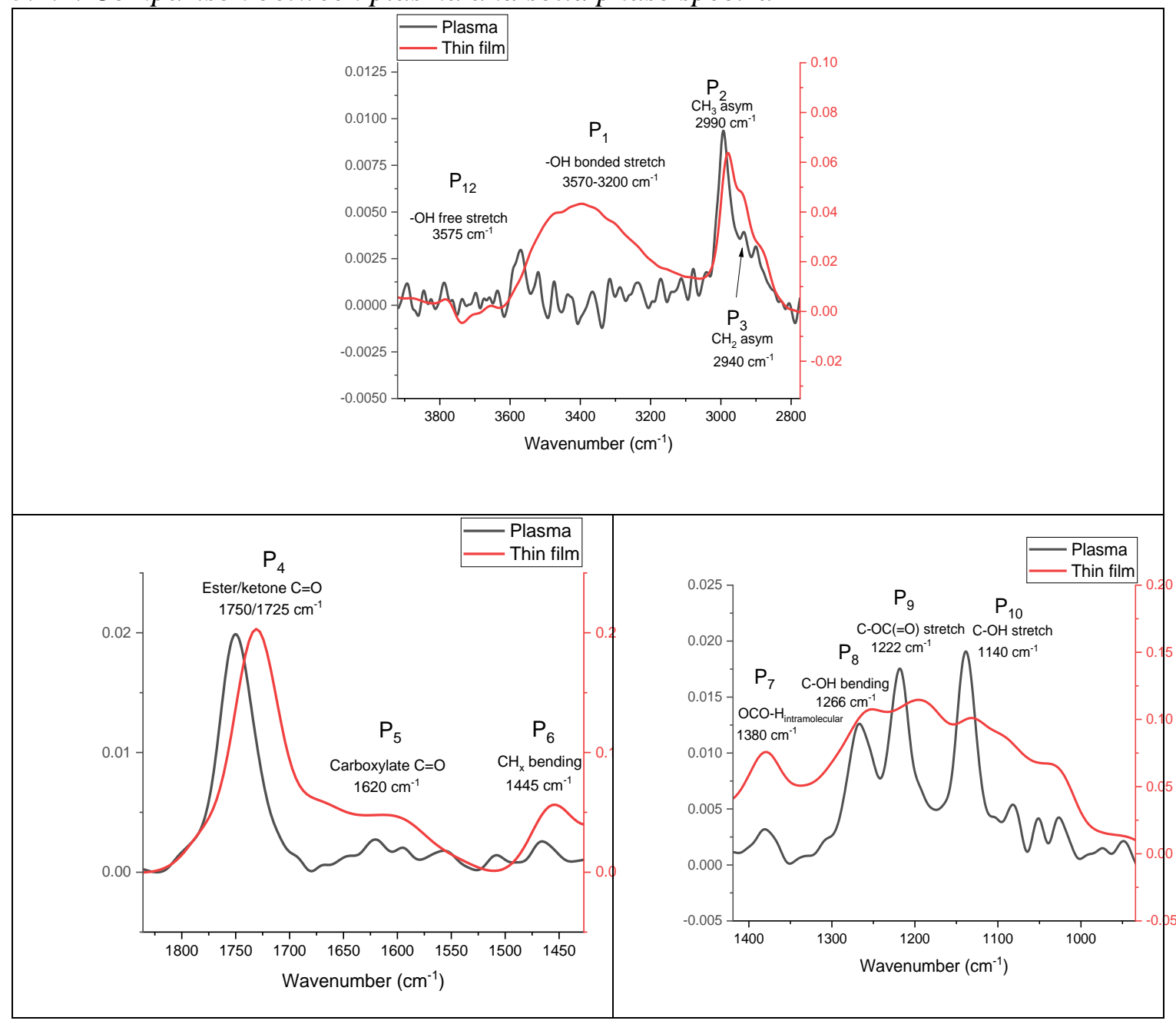


Figure 6. Comparison of EL band evolution in both plasma phase (black) and plasma polymer (red) at $10 \mathrm{~mm}$ for GDBD regime.

Figure 6 compares the plasma and thin film FTIR spectra at the same position in the plasma discharge. At first sight, it has to be emphasized that all of the features observed in the infrared spectrum of the plasma phase are seen in that of the solid film, which means that all of the chemical functionalities of the ethyl lactate molecule are, at least, partly transferred in the chemical structure of the plasma polymerized film. For those infrared bands occurring in both the plasma and the solid phases, the general trend is that infrared peaks of the film are shifted to lower wavenumbers, in agreement with a higher level of order with respect to the plasma phase ${ }^{32,35}$. In addition, the infrared features of the thin film spectrum are also broader, in agreement with the fact that more molecular interactions occur in the solid as opposed to the plasma phase ${ }^{32}$.

Some spectral regions are of particular interest while comparing the chemical composition of both plasma and solid phases. First, the $\mathrm{OH}$ stretching mode vibration $\left(\mathrm{P}_{12}\right)$ does not appear in the spectrum of the plasma, but a rather narrow band with a low absorbance appears at $3575 \mathrm{~cm}^{-1}$ and is assigned to free $\mathrm{OH}$ stretching vibrations $\left(\mathrm{P}_{11}\right)$, as few molecular interactions are likely to occur in the plasma phase. However, in the plasma polymer spectrum, the presence of the $\mathrm{OH}$ groups is rather observed through a much wider feature centered around $3400 \mathrm{~cm}^{-1}\left(\mathrm{P}_{1}\right)$, which reflects the fact that these chemical moieties are involved in several interactions such as hydrogen bonds.

Major differences are also observed while comparing the $\mathrm{C}=\mathrm{O}\left(\mathrm{P}_{4}\right)$ stretching mode vibration region of both the plasma and solid phases. As seen in Figure 6, the infrared 
spectrum of the plasma phase exhibits an absorption at $1750 \mathrm{~cm}^{-1}$, assigned to the ester function of ethyl lactate. In the spectrum of the polymer film, this band is shifted to 1725 $\mathrm{cm}^{-1}$. In addition to the aforementioned ordering effect observed when EL is converted from the plasma to the solid phase, the specific wavenumber value of this infrared component may also be due to the fact that the ester group of the EL molecule is converted into a ketone. This presence of a ketone in the thin film could mean that the preferential group to be dissociated is the $\mathrm{C}-\mathrm{OC}\left(\mathrm{P}_{9}\right)$ group, which is the lowest energy bound of EL.

Of note, another $\mathrm{C}=\mathrm{O}\left(\mathrm{P}_{5}\right)$ stretching mode feature appears near $1600 \mathrm{~cm}^{-1}$ in the infrared spectrum of the plasma polymer film, which is generally assigned to the presence of carboxylate groups. All in all, this means that the EL ester groups are, at least partly, converted into ketones and carboxylic acid functionalities. The $\mathrm{OH}$ components of these latter chemical groups are also likely to contribute to the so-called $\mathrm{C}-\mathrm{OH}$ stretching mode $\left(\mathrm{P}_{10}\right)$ feature observed in the infrared spectrum of the plasma deposited film.

Finally, comparison between the C-OC $\left(\mathrm{P}_{9}\right)$ and $\mathrm{C}-\mathrm{OH}\left(\mathrm{P}_{10}\right)$ stretching mode features $\left(\mathrm{P}_{9}\right.$ and $\mathrm{P}_{10}$ ) for both the plasma and solid phases clearly put in evidence the aforesaid ordering effect along with the increase of the number/intensity of the molecular interactions, as seen through these peaks broadening and shift to lower wavenumbers.

\subsubsection{Thin film polymerization level}

In order to try to probe the level of EL polymerization along the plasma, the infrared $\mathrm{CH}_{2} / \mathrm{CH}_{3}$ ratio $\left(\mathrm{P}_{3} / \mathrm{P}_{2}\right)$ was measured for each investigated position across the plasma 
deposited film. The idea of using this ratio to monitor the EL polymerization level is based on the fact that methyl groups $\left(\mathrm{CH}_{3}, \mathrm{P}_{2}\right)$ are likely to be mostly found at the end of polymeric chains. Accordingly, it is expected that long EL polymeric chains would be characterized by a high $\mathrm{CH}_{2} / \mathrm{CH}_{3}$ infrared ratio with, of course, no polymerization occurring when this spectroscopic parameter is equal to that of pure $\mathrm{EL}^{36,37}$.

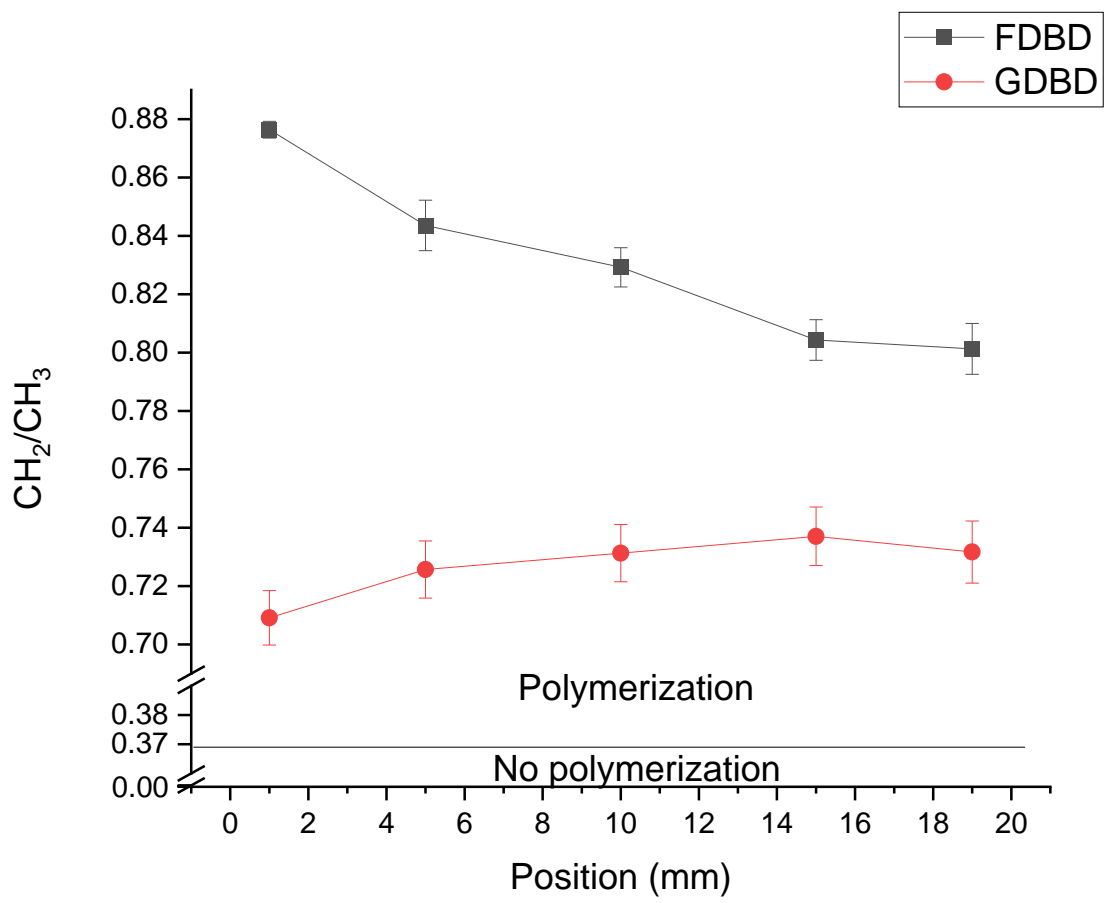

Figure 7. $\mathrm{CH}_{2} / \mathrm{CH}_{3}$ infrared ratio measured from the spectra of plasma polymerized films at positions corresponding to each investigated location in the plasma for FDBD (black) and GDBD (red). The horizontal line indicates the $\mathrm{CH}_{2} / \mathrm{CH}_{3}$ ratio for pure gaseous EL (no polymerization).

According to the defined criteria, Figure 7 shows that the plasma polymerized film deposited under the FDBD regime is more polymerized than the GDBD for all investigated 
positions and GDBD shows a greater uniformity in the polymerization throughout all the positions of the coating.

\subsection{Thin film coating and the DBD chemistry}

In order to try to follow the incorporation of the various EL chemical groups within the plasma deposited films, the absorbance of some of the infrared features of these coatings were ratioed to the absorbance of the $\mathrm{C}=\mathrm{O}$ stretching mode peak $\left(\mathrm{P}_{4}\right)$. The absorbance of this latter feature was fairly constant throughout the length of the plasma deposited film (results not shown). These ratios were, in turn, divided by their corresponding counterparts measured from the infrared spectrum of liquid EL. In other words, these calculations $\left(A_{N}\right)$ enable comparing the thin film and liquid EL composition, in terms of their respective relative amount of a given chemical group and the carbonyl functionality, and are described by the following mathematical equation:

$$
A_{N}=\frac{A_{B T F} / A_{C=O T F}}{A_{B L} / A_{C=O L}}
$$

where $A_{B}$ TF is the absorbance of the infrared features of interest in the plasma deposited thin films, $\mathrm{A}_{\mathrm{C}=\mathrm{O}} \mathrm{TF}$ is the absorbance of the $\mathrm{C}=\mathrm{O}$ stretching mode band in the thin film, $\mathrm{A}_{\mathrm{B}}$ $\mathrm{L}$ is the absorbance of the so-called peaks of interest in liquid EL, and $\mathrm{A}_{\mathrm{C}=\mathrm{O}} \mathrm{L}$ is the absorption of $\mathrm{C}=\mathrm{O}$ in the liquid EL. Accordingly, a $\mathrm{A}_{\mathrm{N}}$ value lower than 1 means that the relative amount of a given chemical group, as compared with the carbonyl functionalities, 
is lower in the film than in the EL molecule, whereas a $A_{N}$ value higher than one signifies that the plasma polymerized film contains relatively more of the chemical functionality of interest with respect to what is observed in the EL molecule.

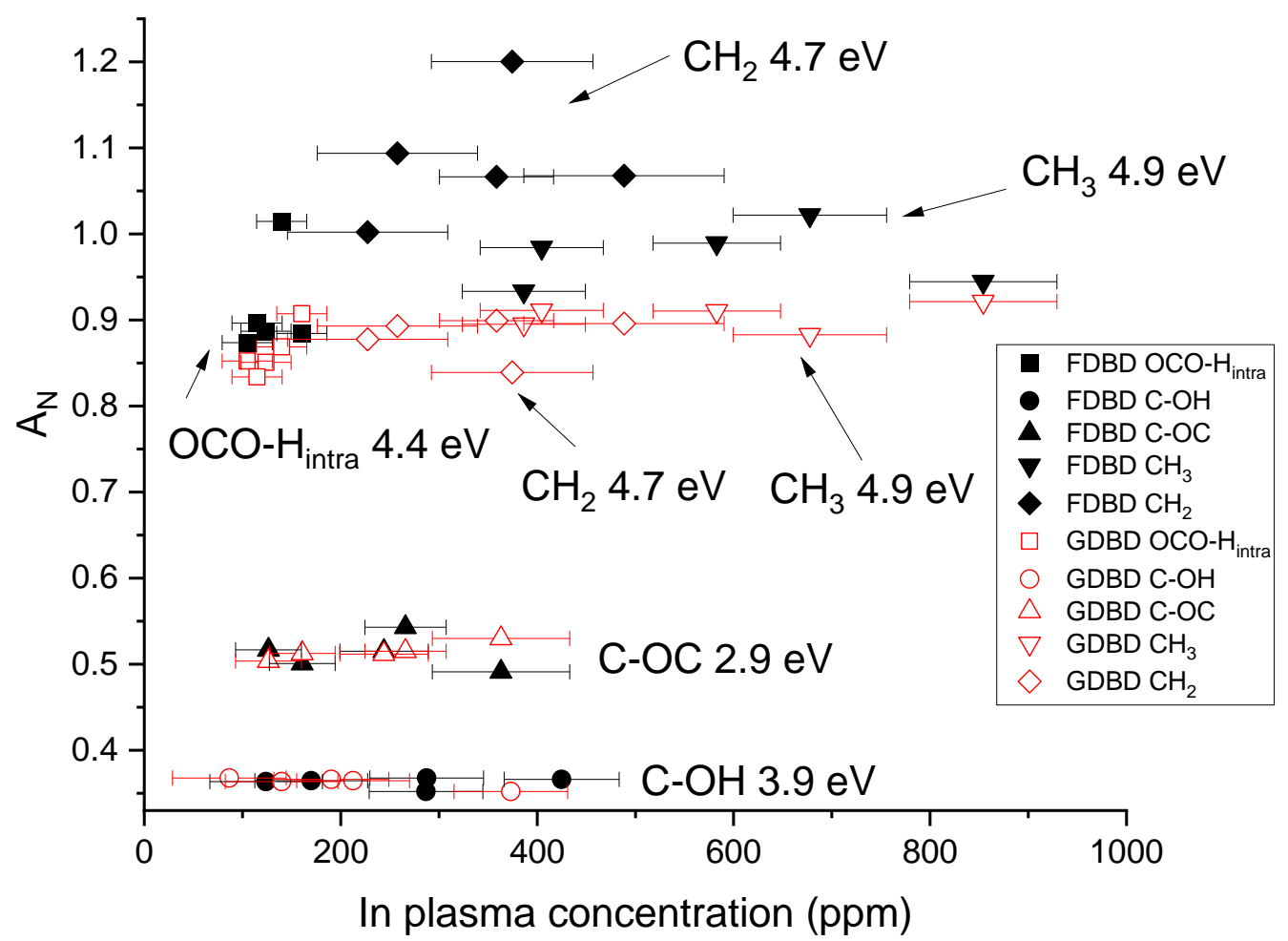

Figure 8. Normalized thin film absorbance of different bonds as a function of the FDBD and GDBD plasmas concentration by the same bond.

Figure 8 shows the results of these calculations made by correlating the information originating from infrared spectra recorded at identical positions in the plasma phase and deposited thin films for both FDBD and GDBD regimes. 
Very interesting observations can be drawn from this figure. From a general standpoint, and regardless of the plasma regime, the amount of a given chemical species in the plasma polymerized film does not depend on this chemical functionality concentration within the plasma, as all relationships between $A_{N}$ and the in-plasma species concentrations can be fairly well described by a horizontal line. For example, $A_{N}$ measured from the C-OC spectral contribution $\left(\mathrm{P}_{9}\right)$ only slightly varies around a value of 0.5 with, however, a rather large variation of the concentration of this chemical functionality in the plasma, that spans from approximately 100 to $350 \mathrm{ppm}$. Of note, the in-plasma concentration of the OCO$\mathrm{H}_{\text {intra }}$ group $\left(\mathrm{P}_{7}\right)$ is almost identical (approx. $100 \mathrm{ppm}$ ) for both plasma regimes and positions. Second, and also regardless of the plasma regime, the relative amount of oxygencontaining species is clearly lower in the plasma polymerized film than in the EL precursor molecule. This is in agreement with the data presented in Figure 5 which show that some of the EL oxygen-containing species are converted in $\mathrm{CO}_{2}$, therefore not being available anymore to be incorporated in the plasma polymer film. Third, the hydrocarbon moieties are the only ones that are observed in greater relative amount in the plasma coating as compared to the EL molecule. For these latter moieties, the plasma regime clearly has an influence as relatively more $\mathrm{CH}_{2}$ and $\mathrm{CH}_{3}$ groups are incorporated in the plasma coating with respect to the EL molecule in the FDBD regime while an opposite behavior is observed in the GDBD mode. In the FDBD regime, the $\mathrm{A}_{\mathrm{N}}$ values calculated for $\mathrm{CH}_{2}$ groups are all higher than the corresponding data for $\mathrm{CH}_{3}$ functionalities, in agreement with the results presented in Figure 7, which shows more precursor polymerization in the 
filamentary mode. It is also interesting to highlight the fact that the preservation of a given chemical functionality from the precursor to the plasma coating is not necessarily related to the bonding energy. For instance, the $\mathrm{C}-\mathrm{OC}(2.9 \mathrm{eV})$ chemical groups are more "preserved" in the plasma polymer structure than the $\mathrm{CO}-\mathrm{H}(3.9 \mathrm{eV})$ functionalities. This emphasizes the fact that the inherent reactivity of chemical groups should also be taken into account to explain the decomposition mechanisms of organic precursors within plasma. 


\section{Conclusions}

This research has compared ethyl lactate decomposition in the plasma and thin film deposition using atmospheric pressure Ar DBD in both filamentary and glow regimes. The power of the GDBD is 4 times that of the FBDB. Measurements were made as a function of the position along the gas flow e.g., EL residence time in the plasma, which is directly correlated to the energy provided per EL molecule.

The analysis consisted of a thorough space resolved study and comparison of the FTIR spectra in the plasma phase and of the thin films. Given the plethora of absorption bands present in the ethyl lactate infrared spectrum, the most characteristic features with known assignments have been selected for analysis of the two phases.

In the FDBD regime, the analyses suggest that etching could be occurring from the already deposited layer, which results in oscillations of the concentration of the chosen absorption bands in the IR spectra of the plasma phase. Moreover, in certain cases the amount of the observed fragment is greater in the plasma phase than that of the injected precursor, reaffirming the etching hypothesis. For the GDBD regime, the decomposition of EL is much more gradual throughout the plasma width and generally results in a greater decomposition than that of FDBD when the same time of residence is taken into account.

As a result of bond dissociation, $\mathrm{CO}_{2}$ creation is observed in both regimes. In GDBD, there is an quadratic relationship between the production of $\mathrm{CO}_{2}$ and the consumption of $\mathrm{C}-\mathrm{OC}$ groups. In $\mathrm{FDBD}, \mathrm{CO}_{2}$ formation requires less energy than in GDBD, perhaps related to the high electron density of the microdischarges, resulting in $\mathrm{CO}_{2}$ saturation early 
in the plasma zone. On the other hand, the FDBD regime shows a linear correlation between decomposition of $\mathrm{C}=\mathrm{O}$ and $\mathrm{CO}_{2}$ creation. The larger GDBD power allows to reach $40 \mathrm{ppm}$ of $\mathrm{CO}_{2}$ compared to $25 \mathrm{ppm}$ in FDBD.

Moreover, the $\mathrm{CH}_{2} / \mathrm{CH}_{3}$ peak height intensity ratio measured from the infrared spectra of plasma deposited films demonstrates that the polymerization level is higher when using the FDBD regime as opposed to the GDBD mode, but the polymerization in the coating created with GDBD is more homogenous throughout the coating.

The analysis of the deposited layer as a function of the decomposition of the molecule in the plasma phase showed that there is a dependency of the bond dissociation energy and the preservation of a fragment in the plasma polymer, as the bonds with highest energies are deposited in a greater amount in the coating, and the opposite is seen for the low energy bonds. Another noteworthy observation was that not only the bond dissociation energy, but also the fragments reactivity plays a role in the decomposition mechanisms and the amounts of that fragment being deposited on the substrate, as seen for $\mathrm{C}-\mathrm{OH}$, which despite the higher dissociation energy than C-OC is less preserved on the coating. 


\section{Conflict of interest}

The authors claim no conflict of interest.

\section{Acknowledgements}

This work was supported by French "Investments for the future" ("Investissements d'Avenir") program managed by the National Agency for Research (ANR) under contract ANR-10-LABX-22-01 (labex SOLSTICE). The financial support of the Natural Science and Engineering Research Council (NSERC) of Canada is also acknowledged. N. Milaniak is the recipient of a scholarship from the Fondation du Centre de Recherche du CHU de Québec-Université Laval.

We would also like to acknowledge the work of Jean-Paul Hoang Hoa Dung for help with obtaining the data for the calibration curves. 


\section{References}

1. Alexandrov SE, McSporran N and Hitchman ML. Remote AP-PECVD of Silicon Dioxide Films from Hexamethyldisiloxane (HMDSO). Chemical Vapor Deposition 2005; 11: 481-490. DOI: 10.1002/cvde.200506385.

2. Hopfe V, Rogler D, Maeder G, et al. Linear Extended ArcJet-CVD - a New PECVD Approach for Continuous Wide Area Coating Under Atmospheric Pressure. Chemical Vapor Deposition 2005; 11: 510-522. DOI: 10.1002/cvde.200406343.

3. Hopfe V, Spitzl R, Dani I, et al. Remote Microwave PECVD for Continuous, Wide-Area Coating Under Atmospheric Pressure. Chemical Vapor Deposition 2005; 11 : 497-509. DOI: 10.1002/cvde.200406352.

4. Kang S, Mauchauffe R, You YS, et al. Insights into the Role of Plasma in Atmospheric Pressure Chemical Vapor Deposition of Titanium Dioxide Thin Films. Sci Rep 2018; 8: 16684. 2018/11/14. DOI: 10.1038/s41598-018-35154-4.

5. Alexandrov SE and Hitchman ML. Chemical Vapor Deposition Enhanced by Atmospheric Pressure Non-thermal Non-equilibrium Plasmas. Chemical Vapor Deposition 2005; 11: 457-468. DOI: 10.1002/cvde.200500026.

6. Bazinette R, Subileau R, Paillol J, et al. Identification of the different diffuse dielectric barrier discharges obtained between $50 \mathrm{kHz}$ to $9 \mathrm{MHz}$ in $\mathrm{Ar} / \mathrm{NH} 3$ at atmospheric pressure. Plasma Sources Science and Technology 2014; 23: 035008035006. DOI: 10.1088/0963-0252/23/3/035008.

7. Al-Abduly A and Christensen P. An in situa nd downstream study of non-thermal plasma chemistry in an air fed dielectric barrier discharge (DBD). Plasma Sources Sci Technol 2015; 24. DOI: 10.1088/0963-0252/24/6/065006.

8. Mustafa MF, Fu X, Liu Y, et al. Volatile organic compounds (VOCs) removal in non-thermal plasma double dielectric barrier discharge reactor. J Hazard Mater 2018; 347: 317-324. 2018/01/15. DOI: 10.1016/j.jhazmat.2018.01.021.

9. Lee B, Kim D-W and Park D-W. Decomposition of Heptane by Dielectric Barrier Discharge (DBD) Plasma Reactor Having the Segmented Electrode: Comparison of Decomposition Mechanisms to Toluene. Plasma Chemistry and Plasma Processing 2019; 40: 61-77. DOI: 10.1007/s11090-019-10024-7.

10. Ligot S, Renaux F, Denis L, et al. Experimental Study of the Plasma Polymerization of Ethyl Lactate. Plasma Processes and Polymers 2013; 10: 999-1009. DOI: 10.1002/ppap.201300025.

11. Ligot S, Guillaume M, Raynaud P, et al. Experimental and Theoretical Study of the Plasma Chemistry of Ethyl Lactate Plasma Polymerization Discharges. Plasma Processes and Polymers 2015; 12: 405-415. DOI: 10.1002/ppap.201400123.

12. Ligot S, Guillaume M, Gerbaux $\mathrm{P}$, et al. Combining mass spectrometry diagnostic and density functional theory calculations for a better understanding of the plasma polymerization of ethyl lactate. J Phys Chem B 2014; 118: 4201-4211. 2014/03/26. DOI: 10.1021/jp411244x.

13. Watson S, Nisol B, Lerouge S, et al. Energetics of Molecular Excitation, Fragmentation, and Polymerization in a Dielectric Barrier Discharge with Argon Carrier 
Gas. Langmuir 2015; 31: 10125-10129. 2015/09/08. DOI:

10.1021/acs.langmuir.5b02794.

14. Massines F, Sarra-Bournet C, Fanelli F, et al. Atmospheric Pressure Low

Temperature Direct Plasma Technology: Status and Challenges for Thin Film Deposition. Plasma Process Polym 2012; 9: 1041-1073. DOI: 10.1002/ppap.201200029.

15. Massines F, Messaoudi R and Mayoux C. Comparison of polypropylene surface treatment between air filamentary and helium glow dielectric barrier discharges. Plasmas and Polymers 1998; 3: 43-59.

16. Sarra-Bournet C, Turgeon S, Mantovani D, et al. Comparison of AtmosphericPressure Plasma versus Low-Pressure RF Plasma for Surface Functionalization of PTFE for Biomedical Applications. Plasma Processes and Polymers 2006; 3: 506-515. DOI: 10.1002/ppap.200600012.

17. Auras R, Harte B and Selke S. An overview of polylactides as packaging materials. Macromol Biosci 2004; 4: 835-864. 2004/10/07. DOI:

10.1002/mabi.200400043.

18. Nair LS and Laurencin CT. Biodegradable polymers as biomaterials. Progress in Polymer Science 2007; 32: 762-798. DOI: 10.1016/j.progpolymsci.2007.05.017.

19. Chu KS, Schorzman AN, Finniss MC, et al. Nanoparticle drug loading as a design parameter to improve docetaxel pharmacokinetics and efficacy. Biomaterials 2013; 34: 8424-8429. 2013/08/01. DOI: 10.1016/j.biomaterials.2013.07.038.

20. Pandita D, Kumar S and Lather V. Hybrid poly(lactic-co-glycolic acid) nanoparticles: design and delivery prospectives. Drug discovery today 2015; 20: 95-104. DOI: 10.1016/j.drudis.2014.09.018.

21. Milaniak N, Laroche G and Massines F. Atmospheric-pressure plasma-enhanced chemical vapor deposition of nanocomposite thin films from ethyl lactate and silica nanoparticles. Plasma Processes and Polymers 2020. DOI: 10.1002/ppap.202000153. 22. Laurent M, Koehler J, Sabbatier G, et al. Atmospheric Pressure Plasma Polymer of Ethyl Lactate: In Vitro Degradation and Cell Viability Studies. Plasma Processes and Polymers 2016; 13: 711-721. DOI: 10.1002/ppap.201500211.

23. Nisol B, Watson S, Lerouge S, et al. Energetics of reactions in a dielectric barrier discharge with argon carrier gas: IV ethyl lactate. Plasma Processes and Polymers 2016; 13: 965-969. DOI: 10.1002/ppap.201600099.

24. Pereira CSM, Silva VMTM and Rodrigues AE. Ethyl lactate as a solvent:

Properties, applications and production processes - a review. Green Chemistry 2011; 13: 2658. DOI: $10.1039 / \mathrm{c} 1 \mathrm{gc} 15523 \mathrm{~g}$.

25. Yutaka Takahashi, Tetsuo Higuchi, Osamu Sekiguchi, et al. Unimolecular decomposition of ethyl lactate, $\mathrm{CH} 3 \mathrm{CH}(\mathrm{OH}) \mathrm{COOC} 2 \mathrm{H} 5$, upon electron impact.

International Journal of Mass Spectrometry 1998; 181: 89-98. DOI: 10.1016/S13873806(98)14178-7.

26. Laroche G, Vallade J, Bazinette R, et al. Fourier transform infrared absorption spectroscopy characterization of gaseous atmospheric pressure plasmas with $2 \mathrm{~mm}$ spatial resolution. The Review of scientific instruments 2012; 83: 103508. DOI:

10.1063/1.4761925. 
27. Brunet P, Rincón R, Martinez J-M, et al. Control of composite thin film made in an $\mathrm{Ar} /$ isopropanol/TiO2

nanoparticles dielectric barrier discharge by the excitation frequency. Plasma Process Polym 2017; 14: 1700049 (1700041-1700013). DOI: 10.1002/ppap.201700049.

28. Doh H-H and Horiike Y. Gas Residence Time Effects on Plasma Parameters: Comparison between Ar and C4F8. Journal of Applied Physics 2001; 40: 3419-3426. DOI: 10.1143/JJAP.40.3419.

29. Milaniak N, Audet P, Griffiths PR, et al. Interpretation of artifacts in Fourier transform infrared spectra of atmospheric pressure dielectric barrier discharges: relationship with the plasma frequency between $300 \mathrm{~Hz}$ and $15 \mathrm{kHz}$. Journal of Physics D: Applied Physics 2020; 53. DOI: 10.1088/1361-6463/ab4777.

30. al. DMe. Guidelines for Data Acquisition and Data Quality Evaluation in Environmental Chemistry. Analytical Chemistry: 2242-2249.

31. Cottrell TL. The strengths of chemical bonds. 1958.

32. Coates J. Interpretation of Infrared Spectra, A Practical Approach. In: Meyers RA (ed) Encyclopedia of Analytical Chemistry: Applications, Theory and Instrumentation. Toronto: John Wiley \& Sons, 2006.

33. NING Y-C. Interpretation of Organic Spectra. Singapore: Jon Wiley and Sons. 34. Khan AS, Khalid H, Sarfraz Z, et al. Vibrational spectroscopy of selective dental restorative materials. Applied Spectroscopy Reviews 2016; 52: 507-540. DOI: 10.1080/05704928.2016.1244069.

35. Bacher A. Infrared Spectroscopy. University of California: Chem UCLA, 2002. 36. Tillet G, Boutevin B and Ameduri B. Chemical reactions of polymer crosslinking and post-crosslinking at room and medium temperature. Progress in Polymer Science 2011; 36: 191-217. DOI: 10.1016/j.progpolymsci.2010.08.003.

37. Arasi AY, Jeyakumari JJ, Sundaresan B, et al. The structural properties of poly(aniline)--analysis via FTIR spectroscopy. Spectrochim Acta A Mol Biomol Spectrosc 2009; 74: 1229-1234. 2009/10/31. DOI: 10.1016/j.saa.2009.09.042. 